\title{
GUERRA Y TERRORISMO INTERNACIONAL. UN ANÁLISIS DEL LENGUAJE POLÍTICO*
}

\author{
Luigi FERRAJOLI**
}

RESUMEN: En este ensayo acerca de la violencia política, Ferrajoli reflexiona sobre el significado real de términos como guerra y terrorismo, y descubre las irracionales implicaciones que conlleva una deliberada y desacertada respuesta bélica, en vez de otra racional, proveniente del derecho penal, ante un hecho delictivo cometido por un grupo terrorista y no por los inocentes habitantes de naciones enteras. El autor pone en tela de juicio guerras ilegítimas como las promovidas por la administración de Estados Unidos contra Afganistán e Irak, ante los atentados funestos del 11 de septiembre del 2001, y propone la refundación del pacto de convivencia entre las naciones, pues de no ser así, la opción que queda para el futuro es la guerra permanente.

ABSTRACT: In this essay about political violence, Ferrajoli reflects about the real meaning of terms such as war and terrorism. He discovers the irrational implications that entail a deliberated and unfortunate military answer, instead of a rational one that comes from criminal law when a crime has been committed by a terrorist group and not by the innocent habitants of whole nations. The author questions the illegitimate wars, such as those promoted by the United States against Afghanistan and Iraq as an answer to the attacks of September 11, 2001. He also propose the restoration of the pact of connivance between nations, because if not, the only solution for the future will be the permanent war.

RÉSUMÉ: Dans cet essai sur la violence politique, Ferrajoli reflète sur le sens réel de termes comme la guerre et le terrorisme, et découvre les implications irrationnels que conduit un délibère et malheureux réponse militaire, au contraire d'un réponse rationnelle provenant du droit criminel en face de un crime commis par un groupe terroriste et pas pour les habitants innocents des nations entiers. L'auteur mettre en question les guerres illégitimes comme ceux promues par les États-Unis en contre de Afghanistan et Iraq en réponse aux attentats du septembre 11, 2001 et propos la restauration du pacte de cohabitation entre le nations, parce que si non, la seule choix restant pour le future est la guerre incessante.

* Artículo recibido el 25 de febrero de 2008 y aceptado para su publicación el 26 de marzo de 2008. Traducción de Miguel Carbonell.

** Profesor de Filosofía del derecho y de Teoría general del derecho en la Università degli Studi Roma Tre. 
SUMARIO: I. Un análisis del lenguaje sobre el tema de la guerra y el terrorismo. II. Tres novedades de las nuevas guerras. III. Una respuesta racional al terrorismo. La asimetría del derecho y de la política. IV. Una alternativa: guerra permanen-

te o refundación del pacto internacional de convivencia.

\section{UN ANÁLISIS DEL LENGUAJE SOBRE EL TEMA \\ DE LA GUERRA Y EL TERRORISMO}

En ninguna otra materia como en la de la violencia política, los significados asociados a los términos de la cuestión - terrorismo y guerra- son tan decisivos en la determinación de nuestras concepciones en torno a uno y la otra y en la orientación de nuestras elecciones y nuestras prácticas. En relación con estos distintos significados, que no se pueden dar por hecho en el sentido común y en la cultura política corrientes, que se ha dividido la opinión pública mundial sobre posiciones irreductiblemente opuestas: por un lado en apoyo a la guerra como un tipo de respuesta legítima, por el otro contra la guerra, como respuesta criminal, además de ineficaz, a los ataques terroristas. De ahí la necesidad de un control de nuestro lenguaje como presupuesto de cualquier discurso sensato y, sobre todo, de cualquier respuesta racional, incluso antes que legítima, al terrorismo.

La cuestión puede ser formulada a través de una simple pregunta: ¿es el terrorismo una agresión bélica o un fenómeno delictivo, aunque de carácter político? Incluso de forma más concreta: ¿la masacre del 11 de septiembre fue un acto de "guerra", o por el contrario un acto delictivo, como se ha calificado siempre a los actos terroristas? Es claro que si por "guerra" entendemos, según la clásica definición de Alberico Gentili, una "publicorum armorum contentio", es decir, un conflicto armado entre Estados, y precisamente entre ejércitos estatales reconocibles como públicos, esa masacre no tiene ninguna de las connotaciones de la guerra, y tiene todas y únicamente las del delito. Debido a que las guerras se hacen por los Estados, suponen fronteras y territorios, ejércitos regulares y enemigos ciertos y reconocibles; el terrorismo consiste en una violencia puesta en acción por organizaciones ramificadas y ocultas, que operan clandestinamente y que desde el inicio se han escondido, como lo hacen siempre los criminales. 
¿Por qué es importante distinguir, analíticamente, lo que convenimos en entender por "guerra" y lo que, por el contrario, entendemos por "terrorismo"? Porque son profundamente diversas, incluso opuestas, las respuestas que nuestra misma civilización occidental ha suministrado y requiere frente a ambos fenómenos. A un acto de guerra se le responde con la guerra y con la movilización general contra el Estado agresor. A un delito, así sea gravísimo, se le responde con el derecho penal, o sea con el castigo severo de los culpables: no con los ejércitos y los bombardeos contra víctimas inocentes, sino con la policía y con los procedimientos judiciales, y, en consecuencia, antes que nada, por medio de investigaciones conducidas con adecuadas capacidades de análisis dirigidas para determinar las responsabilidades, identificar e individualizar a los autores y neutralizar la compleja red de las complicidades que les han ayudado y lo continúan haciendo.

Pues bien, al terrible atentado del 11 de septiembre la administración de los Estados Unidos ha respondido con la guerra, primero en Afganistán y luego en Irak, justamente porque fue calificado no solamente como acto terrorista sino también como "acto de guerra".

Ahora bien, la guerra ha afectado, como sucede en la lógica de ésta, a miles de inocentes, provocando una espiral inevitable de otros actos de terrorismo, desencadenando y multiplicando ulteriores odios, violencias y fanatismos. Debemos entonces preguntarnos si la guerra, presentada como un acto legítimo de firmeza y de defensa, no es en realidad un signo de debilidad y de autolesionamiento de Occidente: una abdicación de los valores de racionalidad y de civilidad que deberíamos más bien contraponer a la brutalidad del terrorismo. Debemos preguntarnos si no es justamente la guerra, la espiral incontrolable de la violencia y la derrota de la razón y del derecho lo que los terroristas persiguen como su principal objetivo estratégico. Recordemos que en Italia, hace más de veinte años, en el tiempo del terrorismo político, todos -izquierda y derecha, críticos y defensores de las leyes de emergencia, favorecedores y adversarios de los pactos con los terroristas - estábamos de acuerdo en algo: en negarles a los terroristas el estatus de "beligerantes", y, por tanto, en rechazar la lógica de la guerra que los terroristas querían imponerle a nuestro país. Fue para todos muy claro, en esos años, que la respuesta de la guerra, más allá de las cuestiones de principio, jurídicas y morales, es insensata justamente desde el punto de vista de la lucha contra el terrorismo, que como guerra, y por ella, acaba siendo legitimado y alimentado. 
Por lo tanto, es precisamente el distinto valor de las palabras y eficacia de las respuestas - guerra o derecho, represalia o castigo- elaboradas y experimentadas por nuestra tradición para enfrentar la violencia lo que debería ser valorado. Los atentados del 11 de septiembre habrían podido provocar una reflexión sobre la fragilidad de nuestra seguridad y hubieran representado una ocasión para poner en marcha una operación policíaca de alcances planetarios que por primera vez, gracias a la solidaridad general que se desató hacia los Estados Unidos, habría movilizado a las policías y a los servicios secretos de medio mundo con el fin de identificar y capturar a los culpables: sin el clamor y la espectacularidad de la guerra, sino por el contrario con los métodos muchos más eficaces del sigilo y de la coordinación entre las investigaciones, del descubrimiento de todo el mapa de las organizaciones terroristas, de su aislamiento político y de su división interna y, obviamente, del empleo de la fuerza dirigida, en vez de martirizar y aterrorizar a la población civil, desarmar a sus componentes y entregarlos a la justicia. Habría crecido, mundialmente, la credibilidad de Occidente y el propio prestigio de los Estados Unidos. Y quizá no habría sido difícil, sobre esta base, provocar la caída pacífica del régimen de los talibanes, que como se sabe se sostenía sobre todo por las ayudas económicas y militares de Pakistán, e incluso el régimen de Sadam Hussein. Por lo demás, en los días inmediatamente anteriores a los bombardeos, el aislamiento de los talibanes había llegado al punto de provocar divisiones en su interior y de hacerles proponer la entrega de Bin Laden a Pakistán, aunque fuera a condición de que no se le extraditara a los Estados Unidos. Y lo mismo puede decirse de Sadam, a quien la presión internacional, si se hubiera conducido con firmeza e inteligencia, habría seguramente obligado al exilio junto con su familia y con sus cortesanos. Quizá, si hubieran prevalecido la paciencia y la razón, hoy Bin Laden estaría neutralizado.

Pero no fue solamente la calificación del terrorismo como guerra y de la guerra como lucha al terrorismo lo que ha trastornado el lenguaje de la política y del derecho. La manipulación del lenguaje, una vez encauzada, no conoce límites. Hemos asistido, en estos años, a un cambio del significado, en función de su legitimación o deslegitimación, de todas las palabras que tienen que ver con el uso de la fuerza. No sólo la guerra desencadenada por los Estados Unidos, sino también los saqueos, los secuestros de personas, las torturas e incluso los atentados que han realizado los vencedores en los territorios ocupados han sido a su vez llamados 
"lucha contra el terrorismo" en defensa de la democracia y las libertades. Y esta lucha, gracias a un ulterior deslizamiento semántico, ha sido etiquetada como "justa", resolviéndose en la criminalización del enemigo, al que no se le aplican los tratados internacionales sobre el tratamiento de prisioneros de guerra y, a la vez, en la militarización de los procesos, en los que no se aplican las garantías ordinarias de los procesados sino el modelo de lo que se viene llamando, con una contradicción de términos, el "derecho penal del enemigo". Por el contrario, todo lo que contrasta con los métodos de esta lucha, cualquier forma de violencia política e incluso de revuelta, es etiquetado y descalificado como "terrorismo" o "filo-terrorismo". Incluso el "pacifismo jurídico", en este desorden del lenguaje, es utilizado como un insulto, o en el mejor de los casos es desacreditado como una ingenuidad de almas bellas, y en el peor como una ideología desconsiderada e irresponsable, siempre como un rezago frente a la agresión del terrorismo.

Esta mistificación del lenguaje operada por los defensores de la guerra —una guerra de "nuevo" tipo que, a diferencia de las guerras del pasado, se proyecta inevitablemente como "infinita" - es el primer signo amenazador de un posible totalitarismo internacional. Su efecto es la incomprensión de la realidad. Expresiones genéricas como "terrorismo internacional", "jihad islámica mundial" y otras parecidas sirven para englobar a los grupos más dispares, reunidos por las razones más diversas: desde movimientos políticos, como Al-Qaeda; razones nacionalistas como en Chechenia, Palestina o parte de Irak, o motivaciones de carácter étnico, como sucedió en Yugoslavia y como sucede en parte en Afganistán. Está claro que una generalización tan amplia del lenguaje, en virtud de la cual fenómenos diversos son reunidos bajo una única etiqueta, corre el riesgo de favorecer la alianza entre los diversos terrorismos y a la vez el de impedir, por la simplificación maniquea, cualquier conocimiento y comprensión del fenómeno que se intenta combatir. Todo el territorio árabe y del Medio Oriente, en este imaginario simplificado, se identifica con el Islam; éste se identifica con sus componentes más sectarios y fundamentalistas; el fundamentalismo con el terrorismo; el terrorismo, finalmente, con una organización, Al-Qaeda, guiada por un solo líder, Osama Bin Laden, detrás de quien estaría un Estado (primero Afganistán, luego Irak, mañana Irán) al que demonizar, agredir y destruir. Todo esto no tiene nada que ver con la realidad. El propio terrorismo islámico está conformado por grupos distintos, localizados en Irak, Chechenia, 
Egipto, Indonesia, en Europa, cada uno con historias, identidades y motivaciones distintas que solamente la respuesta de la guerra puede unir.

\section{TRES NOVEDADES DE LAS NUEVAS GUERRAS}

\section{El rompimiento del derecho internacional}

Está sucediendo que los fenómenos que debemos comprender y afrontar se hacen más complejos, nuestro lenguaje y nuestras categorías, en vez de hacerse también más complejos y diferenciados, se simplifican y se confunden, hasta su extrema simplificación en la oposición primitiva del "bien" contra el "mal". Es gracias a esta burda simplificación que se ha producido una regresión de las relaciones internacionales, la cual se manifiesta en tres mutaciones relacionadas con la naturaleza y la percepción de la guerra: en primer lugar la violación y luego la negación, por obra de las guerras de los últimos quince años, del derecho internacional nacido de la Carta de la Organización de las Naciones Unidas (ONU), que encuentra en la prohibición de la guerra en ella estipulada a su norma fundamental; en segundo lugar la rehabilitación de la guerra como instrumento de solución de los problemas y las controversias internacionales y de mantenimiento del orden público mundial; en tercer lugar, como consecuencia de los anteriores, el carácter virtualmente infinito y las connotaciones abiertamente terroristas asumidas por las nuevas guerras.

La primera mutación consiste en la pretensión de que las nuevas guerras, aunque violen el derecho internacional, tengan sin embargo una legitimación jurídica. Otras guerras se habían verificado en decenios pasados. Pero nadie había pretendido calificarlas como jurídicamente lícitas. Las nuevas guerras se proponen, por el contrario, sobre la base, o incluso peor, de forma alternativa al derecho internacional, como "usos legítimos de la fuerza": como la única respuesta posible al pacifismo, el cual equivaldría a una suerte de utopía moralista e irreal, indiferente e impotente frente a la criminalidad internacional. El tránsito hacia esta mutación ha implicado, de nuevo, una manipulación del lenguaje y de los conceptos: una suerte de fraude de las etiquetas gracias a la cual la guerra ha sido llamada "acción de policía internacional", o incluso "uso legítimo de la fuerza", en oposición a la impotencia del pacifismo. 
Contra esta ulterior mistificación lingüística es fácil recordar que el principio de la paz, teorizado en los orígenes de la civilización jurídica moderna por Thomas Hobbes como alternativa realista y racional a la guerra permanente, tal como está hoy estipulado en la Carta de las Naciones Unidas no excluye de hecho el uso legítimo de la fuerza. Por el contrario, lo implica, por parte de una autoridad constituida, como medida extrema dirigida, según el artículo 39 de la Carta de la ONU, a "mantener o restablecer la paz y la seguridad internacional". Lo implica, precisamente, bajo la forma del monopolio jurídico de la fuerza - según las palabras de otro clásico del pensamiento político, Max Weber- como necesaria garantía de la prohibición de la guerra, junto a la legitimidad de la autodefensa, siendo imposible sin ella asegurar la prohibición misma y, por tanto, el mantenimiento de la paz. Se trata de la misma implicación expresada por el paradigma normativo del derecho penal, que liga, en los ordenamientos jurídicos internos, la prohibición y prevención de los delitos y de la violencia informal, al monopolio estatal de la fuerza y la legítima defensa: los cuales para nada se excluyen, sino que están lógicamente implicados, como sus garantías, por la prohibición, en la vida civil, de la venganza privada.

No es por tanto la guerra, sino solamente la "acción coercitiva internacional" y "el derecho natural de autotutela", tal como están previstos y regulados por el capítulo VII de la Carta de la ONU, los que integran el "uso legítimo de la fuerza" y por tanto son precisamente las alternativas a la guerra y, a la vez, las garantías de su prohibición. Pero está claro que entre "guerra" y "uso legítimo de la fuerza" bajo las formas mencionadas hay una diferencia radical, que no puede ser ocultada, como se ha hecho, con un simple juego de palabras: llamando "acciones coercitivas", "operaciones de policía" o "legítima defensa" a lo que tiene todas las características empíricas de la guerra.

Es del todo clara la diferencia entre "guerra de agresión" y "autotutela" o "legítima defensa". El "derecho natural de autotutela individual o colectiva" ocurre, según el artículo 51 de la Carta de la ONU, que recalca la noción de legítima defensa definida por todos los códigos penales, "en el caso de que tenga lugar un ataque armado", ya sea para repelerlo o para enfrentarlo. Debe, en suma, haberse producido, para que pueda hablarse de legítima defensa y no de represalia, una agresión armada. Es por tanto extraña y contraria a la Carta de la ONU la figura de la "legítima defensa preventiva" utilizada por la administración estadounidense 
como fundamento de la segunda guerra contra Irak: se trata de una contradicción en términos, con la cual el agresor se transforma en agredido y el agredido en agresor.

Más difícil es trazar exactamente la diferencia entre la guerra y la "acción coercitiva" confiada por el capítulo VII de la Carta al Consejo de Seguridad; incluso porque el artículo 42 de la Carta de la ONU habla, a propósito de las acciones "necesarias para mantener o restablecer la paz", del empleo de "fuerzas aéreas, navales o terrestres". Y sin embargo la diferencia existe. Existe en el plano, esencial en esta materia, de las formas, dado que la decisión y luego la constante "dirección estratégica" del uso de la fuerza está reservado, por el artículo 47 de la Carta, al Consejo de Seguridad. Y existe, sobre todo, en el plano sustancial. La guerra es por naturaleza un uso de la fuerza desmesurado e incontrolado, dirigido al aniquilamiento del adversario y destinado inevitablemente, en sus formas actuales, a golpear a la población civil. El empleo legítimo de la fuerza es solamente el estrictamente necesario no ya para vencer, sino únicamente para mantener o restablecer la paz y la seguridad internacionales y precisamente por esto, en garantía de estos vínculos y de estas finalidades, otorgado constantemente, por el citado artículo 47 de la Carta, "a las dependencias del Consejo de Seguridad". La diferencia entre ambas cosas se manifiesta en dos elementos: la tutela de los inocentes, como lo son las poblaciones civiles, y la no instrumentalización de la coerción para fines o intereses de parte, asegurados ambos por el uso legítimo de la fuerza y no, por el contrario, por la guerra. Ésta es la misma diferencia que existe entre pena y venganza: una es la negación de la otra, y por negación de la otra se define.

Naturalmente, la guerra puede parecer, en el corto plazo, bastante más "eficaz" y resolutiva que el uso regulado de la fuerza bajo el control de la ONU. Pero es justamente en esto en lo que reside la diferencia fundamental entre ambas cosas. El derecho - o sea los tratos pacientes, luego los diversos tipos de sanciones disuasorias y luego el empleo limitado y controlado de la fuerza con sus presupuestos, sus formas y sus límites- es por naturaleza un medio más costoso, más lento y menos eficaz que el uso no regulado de la fuerza en que consiste la guerra. Y entre sus costos se encuentra siempre el riesgo de una cierta inefectividad. Nadie podría sostener que el derecho penal interno es siempre efectivo o incluso que es capaz de erradicar definitivamente la criminalidad. Pero nadie piensa que para derrotar a la criminalidad, aunque esté organizada y ar- 
mada, cualquier medio - la tortura, el bombardeo de las localidades mafiosas, el fusilamiento de los sospechosos- es lícito, o que para detener un robo a un banco la policía deba intervenir con bombas y tanques.

Si todo esto es verdad, entonces ninguna de las cuatro guerras desencadenadas por Occidente en los últimos quince años - las "nuevas guerras" o "guerras globales" como se les ha llamado- ha sido jurídicamente legítima. No lo ha sido ni siquiera la primera guerra contra Irak, en 1991, aunque fue autorizada por el Consejo de Seguridad sobre la base de la necesidad de poner fin a la ilícita ocupación iraquí del territorio de Kuwait. La idea de que la guerra ha sido "autorizada por la ONU" siempre que se reivindica su legitimidad sobre la base de una decisión del Consejo de Seguridad, lleva sobre las espaldas otra confusión lingüística y conceptual: la confusión entre el Consejo de Seguridad y la ONU, entre la ONU como "ordenamiento" y la ONU como sujeto jurídico articulado a través de sus distintos órganos. El Consejo de Seguridad no es de hecho la ONU, sino un órgano de ésta. Y desde luego no es un soberano absoluto, sino que está sometido al derecho y, antes que nada, a su carta estatutaria. No puede, por tanto, ordenar una guerra, sino solamente el uso legítimo de la fuerza previsto y regulado por el capítulo VII de la Carta, y de este uso debe mantener, como dice el artículo 53 de la misma Carta, la directa dirección estratégica, que no es delegable a los Estados en lo individual o a coaliciones de Estados.

Mucho menos son jurídicamente legítimas las otras tres guerras de estos últimos años, que no por nada, al no poder en ningún sentido legitimarse ni siquiera dentro del amparo de la ONU/Consejo de Seguridad, han tenido que recurrir a una reasunción de la teoría premoderna de la "guerra justa" y de sus "justas causas" o finalidades: la tutela de los derechos humanos en la "guerra humanitaria" de la OTAN en la Federación yugoslava; la lucha contra el terrorismo iniciada en Afganistán y continuada luego contra Irak. Dos justificaciones políticas que abiertamente reniegan de la prohibición de la guerra, repropuesta por ellas como acto constituyente e instrumento de defensa de un nuevo orden mundial.

Con estas guerras, respecto a la primera guerra del Golfo, se realiza un salto cualitativo en su relación con el derecho. El derecho internacional vigente y el principio de la paz, que es su norma fundamental, no son simplemente violados. Son abiertamente negados, en nombre de una nueva legitimidad política que pretende imponerse como jurídica. En este sentido, como se ha dicho, estas guerras son al mismo tiempo sub- 
versivas respecto del viejo orden y constituyentes de un nuevo orden internacional: opuesto al primero, porque se basa en la guerra como instrumento de gobierno del mundo y de solución de las controversias internacionales.

\section{La ilusión de un nuevo orden internacional basado en la guerra}

Paso de esta forma al segundo elemento novedoso de las nuevas guerras: su pretensión de auto-legitimación como instrumento para mantener el orden mundial, avanzada en su momento con la justificación de la guerra de Kosovo en defensa de los derechos humanos, y retomada luego, con la justificación de la lucha al terrorismo, en los documentos estratégicos de la administración del presidente George W. Bush.

La primera justificación - de la guerra como instrumento de garantía de los derechos - expresa una absurda contraposición entre derechos y derecho, entre la sustancia de los primeros y las formas de tutela de los mismos ofrecida por el segundo: como si las formas fueran vacíos e insensatos procedimientos y no las técnicas de garantía de los derechos, y el derecho no fuera el sistema de reglas idóneas para impedir, o al menos minimizar, la violencia arbitraria y por ello para garantizar los derechos, además de la convivencia civil y pacífica, tanto estatal como interestatal. La guerra, por el contrario, es una regresión al estado salvaje y la violación masiva de los derechos humanos, primero entre todos es el derecho a la vida de todas las personas involucradas en ella. Debe agregarse que este rompimiento del nexo entre derecho y derechos, expresada por la idea de que los derechos pueden ser tutelados con medios antijurídicos e incluso con la guerra que es su negación, es el síntoma de un nuevo fundamentalismo, que corre el riesgo de oponer el "Occidente de los derechos" al resto del mundo y de reproducir la misma obsesión identitaria que es propia de las guerras étnicas: por un lado Occidente, por el otro el resto del mundo al que se tratan de imponer los "valores occidentales" por medio de la violencia. Es desde luego cierto que Occidente siempre ha justificado sus guerras - cruzadas, conquistas y colonizaciones-en nombre de sus propios valores: primero como misiones de evangelización, luego como misiones de civilización. Pero esta vez la contradicción de las guerras con los valores en nombre de los cuales son realizadas - los derechos humanos en Kosovo, la democracia en Irak, que por su naturaleza excluyen a la guerra y exigen una mediación jurídica- es tan 
vistosa que esos "valores" resultan descalificados como el último engaño de Occidente.

Todavía más insensata y fallida se ha revelado la idea, sostenida con ocasión de las dos últimas guerras, contra Afganistán y contra Irak, de que la guerra puede servir para derrotar al terrorismo. Como se dijo al inicio, el terrorismo internacional es un fenómeno radicado y ramificado en decenas de países, que puede ser enfrentado y derrotado solamente por una red igualmente internacional y ramificada de fuerzas de policía, capaces de identificar a los jefes, las estructuras, los financiamientos y las complicidades, a través de los métodos del sigilo, la profesionalidad investigadora y la coordinación de las investigaciones. Sólo sobre esta base, una vez descubierta la red de las organizaciones terroristas, tiene sentido el empleo regulado de la fuerza, dirigido únicamente a desarmar a sus componentes y a llevarlos ante la justicia. La guerra, por el contrario, con sus inútiles devastaciones, solamente puede agravar, como la gasolina sobre el fuego, los problemas que pretende resolver. Puede satisfacer la sed de venganza, pero siempre causando daño a víctimas inocentes. Puede galvanizar y movilizar a las opiniones públicas. Pero desde luego no sirve para golpear las mil cabezas de las organizaciones terroristas, sino que por el contrario más bien las refuerza.

Es precisamente la guerra, de hecho, el objetivo de todo terrorismo, dado que como guerra, simétricamente, se propone y como tal quiere ser reconocido. Por eso la respuesta al terrorismo es tanto más eficaz cuanto más asimétrica: cuanto más el terrorismo no es elevado al nivel de un Estado beligerante y sus agresiones son reconocidas como delitos y no ya como actos de guerra; tanto menos cuando se le responde con la lógica primitiva de la guerra, simétrica a la del terrorismo porque también ella se dirige inevitablemente contra los inocentes, y opuesta, al igual que el terrorismo, a la lógica del derecho. Lo anterior no impide reconocer que el terrorismo es un fenómeno político, que debe ser entendido y enfrentado también, y sobre todo, políticamente. Pero es justamente en la asimetría respecto al terrorismo por medio de su calificación jurídica como "delito" en lo que reside el secreto de su despotenciamiento y aislamiento y por tanto en el papel del derecho como factor de paz y de civilización: instrumento, justamente, del paso desde el Estado de guerra al Estado de derecho, desde la sociedad salvaje a la sociedad civil.

La prueba de la nula idoneidad de la guerra para derrotar al terrorismo, y menos que nunca para ser un instrumento de mantenimiento del 
orden internacional, nos la ofrece por lo demás su calificación, en los propios documentos de la administración norteamericana, como "guerra infinita" (o bien, gracias a la conocida confusión del lenguaje, como "justicia infinita"). Por lo tanto, a diferencia de las guerras en sentido propio, que se concluyen siempre con la derrota de uno de los Estados contendientes y por ello con la paz, una guerra preventiva en contra de una violencia privada, como lo es el terrorismo, es inevitablemente permanente, siendo una peligrosa ilusión totalitaria la idea de una seguridad absoluta, perseguida no ya con el derecho penal sino con la derrota definitiva de la criminalidad y con la extirpación del mal.

Pero esto equivale a proyectar una regresión planetaria al bellum omnium, es decir a la guerra infinita propia del Estado precivil y salvaje: cuando en el ciclo de la violencia no se había interpuesto todavía la intervención asimétrica del derecho como instrumento de civilización de los conflictos mediante la prohibición, como delitos, de la venganza y de la represalia. Esto se prueba con el hecho de que el terrorismo no ha sido debilitado, sino por el contrario incentivado y reforzado por las dos guerras contra Afganistán e Irak, en el curso de las cuales se ha matado a millares de personas inocentes, mientras que han sobrevivido los que habían sido señalados como sus principales líderes y responsables (comenzando por Bin Laden). En todos estos casos la guerra - más allá del derrocamiento, no suficiente para justificarlas, de odiosos regímenes totalitarios - ha consistido en el castigo, por una suerte de responsabilidad colectiva, de personas inocentes, en contraste con el principio kantiano, propio de la ética moderna, según el cual ninguna persona puede ser utilizada como medio para fines que le son ajenos. Sin contar con que la guerra ha desestabilizado toda la región medio-oriental y ha desencadenado una espiral sin freno de odios, fanatismo, guerras civiles y otras terribles agresiones terroristas.

Aunque son inevitablemente contrarias a la finalidad de derrotar al terrorismo, las nuevas guerras se caracterizan sin embargo, como ya se ha apuntado, por su papel de destrucción del viejo orden normativo y de refundación de un nuevo arreglo en las relaciones internacionales. Es este el segundo elemento de novedad de las guerras globales. Las nuevas guerras son "nuevas" porque con ellas la guerra ha cambiado de naturaleza. No es más ni guerra de conquista, ni de defensa. No sirve más ni para invadir o colonizar nuevos países, ni para prevenir ataques del enemigo. Hoy la guerra tiene una sola finalidad: la de mantener y consolidar el ac- 
tual orden/desorden mundial desigual, fundado en el dominio americano. En este sentido, es "preventiva": pues su finalidad no es ya la de prevenir improbables agresiones bélicas entre Estados (la última guerra en sentido tradicional fue, en este aspecto, la guerra inglesa por las islas Falkland), ni mucho menos la de prevenir ataques terroristas, dado que el terrorismo no es enfrentado sino alimentado por la guerra, sino la de prevenir conatos de autodeterminación política y económica y, sobre todo, las tentaciones de cualquier otra fuerza, también en los países no agredidos, de poner en cuestión el dominio de la superpotencia americana. Son por tanto un instrumento terrorista de gobierno. En este sentido son preventivas: en el sentido de que son ejemplares. Tienen la misma función que el uso terrorista de la fuerza en un ordenamiento despótico. El mensaje principal es: no tenemos obstáculo. El instrumento es la fuerza de las armas en función represiva, más que preventiva. El criterio, más allá del mantenimiento del actual arreglo global, es la venganza - la represalia, contra el atentado de las Torres Gemelas - en el sentido primitivo de la venganza de la sangre, que golpea al grupo adversario, incluso al inocente.

\section{Las connotaciones terroristas de las nuevas guerras y el neo-fundamentalismo de Occidente}

Hay además una tercera novedad de las guerras actuales, que se expresa en otro aspecto de la relación entre guerra y terrorismo; se ha dicho que se alimentan el uno al otro: ni la guerra puede derrotar al terrorismo, ni el terrorismo puede derrotar a la guerra. Podemos ahora añadir que ambos tienden a parecerse, el uno y la otra como violencias indiscriminadas que golpean a inocentes; el uno y la otra como regresión al estado de naturaleza de las relaciones internacionales, en una espiral en el que uno y otra se alimentan.

Esta semejanza consiste en el hecho de que las nuevas guerras han asumido connotaciones terroristas. Si es verdad que el terrorismo consiste en una violencia indiscriminada, dirigida a provocar terror entre los inocentes, también estas nuevas guerras, si no por otra cosa al menos por la disparidad de las fuerzas sobre el terreno, han asumido formas terroristas, manifestándose en masacres masivas — las guerras desde el cielo, los bombardeos, los saqueos indiscriminados- de las poblaciones civiles. Sus víctimas, al igual que las del terrorismo, son todas y solamente personas inocentes. Su inmoralidad e ilegalidad, por otro lado, son de tal 
modo radicales que, luego del solemne repudio de la guerra como "flagelo" contenido en la Carta de la ONU y en muchas constituciones nacionales, solamente se han podido acreditar en estos años en nombre de una moral absoluta.

También bajo este aspecto el terrorismo y la guerra preventiva son, no por casualidad, fenómenos simétricos. Tanto una como el otro expresan y se basan en otros tantos fundamentalismos religiosos: el fanatismo religioso de la jihad islámica, al que se corresponde el opuesto fanatismo religioso de la guerra preventiva en nombre del dios cristiano o incluso de los "valores" de Occidente, una y otra legitimadas como lucha del bien absoluto contra el mal absoluto. Parece que asistimos a un retorno de las viejas guerras de religión: la guerra ética en nombre de los derechos humanos en Kosovo, y de la democracia en Irak, es decir de los valores a imponer con la fuerza de las armas.

Solamente gracias al relanzamiento de la religión (cristiana) como factor de identidad contrapuesto al Islam, ha sido posible en suma acreditar, con la nueva visión maniquea que informa la política americana, las nuevas guerras de agresión. Naturalmente que los reclamos ético-religiosos - al Dios cristiano de los teocons, a los valores de Occidente, a la lucha del bien contra el mal y otros parecidos - sirven muy bien para encubrir los verdaderos intereses en juego: los de una economía salvaje y agresiva, que no admite reglas, ni límites, ni controles. Y sin embargo sirven para modificar radicalmente la política, insertando en ella una suerte de cognitivismo ético y de fundamentalismo político que induce a configurar lo diferente como enemigo y al disidente como su más o menos consciente aliado.

Es el paradigma schmittiano del amigo/enemigo, que se está imponiendo en las democracias occidentales y sobre todo en los Estados Unidos; el cual, sin embargo, no es, como lo entendía Schmitt, el paradigma de la política, fundado en la mediación, en el compromiso y en el conflicto pacífico, sino el opuesto de la guerra, que es la negación de la política: de la guerra externa como guerra permanente, preventiva y destructora de otros pueblos y países, y de la guerra interna como estado de excepción igualmente permanente, fundado en el miedo, la intolerancia, la exclusión y la negación de los "otros" y de los "diferentes". La identificación del enemigo, en esta lógica, deviene un factor indispensable de la propia identidad y de la legitimación de la política por cualquier medio, incluida la guerra. El esquema, por lo demás, no es nuevo en la 
política norteamericana, que siempre ha tenido la tendencia a auto-representarse como lucha del bien contra el mal. Ayer el enemigo era el comunismo, hoy lo es el terrorismo, representado no sólo como "enemigo externo" sino también como "enemigo interno": para legitimar, además de la guerra externa, la guerra interna contra el sospechoso enemigo interno, dado que es subversivo y connivente con el externo, y a través de ellos la reducción de las libertades de todos.

Todo esto, evidentemente, no tiene nada que ver con la lucha contra el terrorismo y con la defensa de la seguridad. En vez de debilitar al terrorismo, la guerra ha determinado el contagio y su difusión masiva en Irak, donde el terrorismo no existía y donde está provocando decenas de muertos cada día. Ha reforzado sus razones perversas, elevándolo al nivel de un Estado beligerante, acreditando a un crimen horrible como el primer acto de una guerra santa y transformando así, a los ojos de millones de musulmanes, a Bin Laden en un jefe político y a su banda de asesinos en la vanguardia de un ejército de resistentes. Preanunciándose como guerra "infinita", ha provocado innumerables víctimas civiles, sin golpear mínimamente a las mil cabezas de las redes terroristas, presentes en decenas de países, de las que por el contrario ha consolidado las bases de consenso y las capacidades de reclutamiento. Ha hecho crecer el antiamericanismo y el antioccidentalismo en todo el mundo, particularmente en los países islámicos, disolviendo el crédito y la solidaridad adquiridos por los Estados Unidos luego de los atentados.

Desde luego que es verdad que la guerra ha derrotado a un régimen feroz y sanguinario como el de Sadam Hussein, lanzando con las elecciones del 30 de enero del 2005 un vago y del todo improbable proceso de democratización. Pero no es verdad que por esto la guerra fue iniciada. La guerra fue desencadenada por dos razones que desde el principio sonaban falsas: la sospecha de que el Irak de Sadam Hussein disponía de armas de destrucción masiva y que fuese un aliado de Al Qaeda. En todo caso las elecciones en Irak no pueden ser invocadas como cobertura póstuma de una guerra tan ilegal como irracional respecto de cualquier objetivo que no sea la afirmación del dominio estadounidense: dado que la democracia no es exportable con las armas y porque de todas formas, al menos en nuestra civilización jurídica y política, el fin no justifica los medios, sobre todo si los medios consisten en el asesinato de decenas de miles de personas inocentes. 


\section{UNA RESPUESTA RACIONAL AL TERRORISMO. LA ASIMETRÍA DEL DERECHO Y DE LA POLÍTICA}

No sólo el terrorismo, sino también la guerra, con la espiral de violencia que desencadena, representan un peligro para nuestra seguridad y para el futuro de nuestras democracias. El peligro, en otras palabras, proviene también de nosotros, es decir de la naturaleza de las respuestas al desafío del terrorismo. Estas respuestas pueden envenenar nuestra propia democracia: no sólo profundizando el foso cultural y político además de económico, entre Occidente y el resto del mundo, sino también barbarizando nuestro sistema penal y procesal, reduciendo las libertades de todos, favoreciendo desarrollos autoritarios y degeneraciones policíacas, corrompiendo el derecho y la política y, a la vez, disolviendo las reglas de la convivencia internacional como consecuencia de la lógica de guerra del amigo/enemigo. Esta lógica y su validez simbólica son no solamente simétricas, sino convergentes con la del terrorismo; cuyo objetivo, repito, es desencadenar la guerra porque como guerra, simétricamente, se propone y quiere ser reconocido en el plano, precisamente, simbólico. Por esto la respuesta al terrorismo es tanto más racional y eficaz cuanto más es asimétrica: cuanto más se le responde con la lógica contraria de la razón jurídica y política. Derecho y política, de hecho, son las dos respuestas completamente asimétricas respecto a la violencia brutal del terrorismo, justamente porque respecto a ella están dotadas de la mayor capacidad de aislamiento y de deslegitimación.

Sobre todo el derecho, la violencia terrorista - los asesinatos, los atentados, los secuestros de personas, las decapitaciones de inocenteses de hecho reconocible como criminalidad, y como tal despotenciable políticamente y deslegitimable jurídicamente, sólo si es leída y tratada con el lenguaje y con las formas del derecho: con la determinación de las responsabilidades, con las garantías del debido proceso, con la aplicación de las penas previstas por la ley. Es en esta asimetría que reside la diferencia, o mejor dicho la antinomia y la contradicción, entre derecho y guerra, entre pena y violencia. Y es la reducción de esta asimetría entre Estado y terrorismo, entre la reacción legal a la violencia criminal y la criminalidad misma, la causa profunda del fracaso de la guerra preventiva. La respuesta demagógica de la guerra, a su vez ilegal y terrorista, anulando la asimetría entre Estados y terrorismo, entre instituciones públicas y criminalidad, ha privado a los primeros de su mayor fuerza polí- 
tica y los ha puesto al nivel del terrorismo, o, lo que es lo mismo, ha elevado al terrorismo a su nivel - al nivel de un Estado beligerante - como enemigo, en vez de criminal, apuntando hacia la guerra infinita, como infinitas son todas las espirales de la violencia no interrumpidas por la intervención del derecho. Se podría, bajo este aspecto, formular un principio general en materia de violencia política ilegal. Justamente a causa de la asimetría entre derecho y criminalidad, entre Estado y terrorismo, son siempre las instituciones públicas, cuando violan sus propias reglas aunque sea en respuesta a una eversión, las primeras y principales responsables del rompimiento del pacto de convivencia y con eso del Estado de derecho. Rompiendo el pacto - con la guerra externa o con la guerra interna - anulan esa asimetría, sobre la cual se basa su carácter público y jurídico, produciendo una regresión del Estado civil al estado de naturaleza. Recomponer esta asimetría es por tanto la primera respuesta al terrorismo: a través de la rehabilitación del derecho internacional y del papel de las Naciones Unidas, la realización aunque sea progresiva y tendencial de un monopolio internacional de la fuerza por medio de la actuación del artículo 43 de la Carta de la ONU, la coordinación transnacional de las fuerzas de policía y la generalización o el reforzamiento de la justicia penal supraestatal inaugurada con la institución de la Corte Penal Internacional.

La segunda respuesta es la de la política. El presupuesto elemental de la lucha contra el terrorismo es que Occidente sea finalmente creíble, tomando en serio sus propios principios: la tolerancia, la igualdad, la garantía de los derechos de todos. Después del 11 de septiembre, todos repiten que el mundo ha cambiado. Pero no siempre están dispuestos a sacar, de los cambios acontecidos, las consecuencias lógicas. ¿Qué es lo que ha cambiado en el horizonte de la política? Ha cambiado, esencialmente, nuestra subjetividad como ciudadanos occidentales. Ese terrible atentado puso en crisis la ilusión de la seguridad y de la invulnerabilidad de nuestro mundo. Naturalmente que se han producido, en los últimos cincuenta años, otras tremendas y no menos devastadoras tragedias. Pero nunca había sucedido, desde hace más de medio siglo, que un país occidental sufriera una agresión con miles de muertos como la del 11 de septiembre. El susto provocado por la catástrofe no se debe sólo al horror de la carnicería, sino también al miedo, que tuvimos por vez primera, de ser también nosotros víctimas de las guerras y las masacres que ensangrientan el planeta: un miedo tanto más fuerte y angustiante dado que el enemi- 
go es invisible y sus posibilidades de agresión son tanto imprevisibles como no prevenibles.

Hay, por tanto, otra ilusión que el terrible atentado del 11 de septiembre ha disuelto o, mejor, debería haber disuelto: la ilusión de que el Occidente rico y el resto del planeta son mundos separados; que el mundo, que creíamos unificado sólo por el mercado pero rígidamente dividido por fronteras y fortalezas, no es un único mundo también por lo que se refiere a la vida y la seguridad, y que basta, para gobernarlo, la superioridad militar de los Estados Unidos o de la OTAN. El atentado de las Torres Gemelas nos ha dicho por el contrario que no hay más un "exterior" y un "en otro lugar"; que estamos todos en el mismo barco y que el barco es extremadamente frágil. Terminada la división del mundo en bloques, entrados en crisis los Estados y sus soberanías, una política a la altura de los desafíos actuales no puede ser más que la que Jürgen Habermas ha llamado una "política interna del mundo": interna por lo que se refiere a la seguridad contra el terrorismo, dado que hoy en día la seguridad en el mundo es indivisible y la inseguridad es tan global como el mercado y la economía; pero también, si es verdad que la inseguridad es generada por odios y conflictos a los que hay que entender para poder remover sus causas, una política interna del mundo dirigida a los otros problemas vitales del planeta: la pobreza, el hambre, las enfermedades curables e incurables, responsables cada año de decenas de miles de muertes. Vivimos todos en un mismo planeta que se ha hecho cada vez más pequeño por la globalización. Y por tanto, la política más insensata y suicida es la de oponer el odio al odio, la guerra terrorista a la violencia terrorista, en vez de interrogarnos sobre las razones del odio e intentar terminarlas. En el interés de nuestra seguridad. Recordemos la frase en la que Hobbes advierte, en defensa de la conveniencia racional para todos del pacto de convivencia pacífica, que también el más fuerte está obligado a dormir y por tanto está expuesto a los ataques de los más débiles.

\section{UNA ALTERNATIVA: GUERRA PERMANENTE O REFUNDACIÓN DEL PACTO INTERNACIONAL DE CONVIVENCIA}

No sabemos si la guerra en Irak es la primera guerra global del tercer milenio, como lo declaró George W. Bush, o la última del siglo que ha terminado. Sí sabemos que la alternativa que hoy en día se vislumbra 
- frente a un terrorismo potente y fanatizado, que puede hacerse intérprete, además de síntoma perverso, de las muchas tragedias del planetaes entre desarrollo de una guerra civil mundial de tipo endémico, que Occidente podrá combatir con la bomba atómica pero que tendrá de todas maneras solamente vencidos y no vencedores, y una refundación del pacto constituyente que dio vida, hace medio siglo, a las Naciones Unidas; entre la inseguridad global de una sociedad mundial salvaje y una "política interna del mundo" que se haga cargo, con una adecuada proyección jurídica, tanto de la represión como de la prevención de los crímenes contra la humanidad.

Esta segunda alternativa podrá prevalecer, a largo plazo, solamente si alcanzamos la conciencia de que somos todos vulnerables y, a la vez, de que estamos todos involucrados (y somos corresponsables) en los grandes problemas y en las grandes tragedias del mundo. Se ha terminado la ilusión de que el mercado puede ser la única ley de la convivencia mundial y de que nosotros los occidentales podemos mantener pacíficamente nuestros desahogados y despreocupados ritmos de vida mientras miles de millones de seres humanos están condenados a vivir en condiciones inhumanas. Si queremos garantizar nuestra seguridad, debemos hacernos cargo de los problemas del mundo como si fueran nuestros problemas: si no por razones morales y jurídicas, al menos por conveniencia, en defensa de nuestros propios intereses.

Es incluso posible que, por el miedo, prevalezca la razón. Así como nació la ONU, no de forma distinta a la Unión Europea, de un "nunca más" frente a los horrores de las guerras y de los fascismos, también la necesidad de oponer un "nunca más" a este nuevo terrorismo global y a tantos otros y no menos graves crímenes contra la humanidad, podrá tal vez relanzar el proyecto de un orden internacional fundado en la globalización no sólo de los mercados y de la economía, sino también de la política, de la seguridad, del derecho y de los derechos. No olvidemos que la construcción del Estado moderno y de una esfera pública idónea para garantizar la paz, el orden y la seguridad internos fue simultánea y funcional para el nacimiento y el desarrollo del capitalismo. Hoy en día, a la crisis de los Estados nacionales, y por tanto del papel desarrollado en el pasado por las esferas públicas estatales, no se ha correspondido la construcción de una esfera pública internacional a la altura de los procesos de globalización en marcha que se dirija a la tutela de los intereses generales como la paz, la seguridad, la protección del ambiente y la garantía de 
esos derechos de todos que son los derechos fundamentales. Faltan no solamente las garantías de la paz y de tantos otros derechos humanos que están solemnemente proclamados como el fin y la razón social de las Naciones Unidas. Faltan, incluso antes, las instituciones internacionales dedicadas a las correlativas funciones de garantía, esto es a la salvaguarda de la paz y a la tutela de los derechos.

Es la construcción de esta esfera pública internacional, y específicamente la creación de las adecuadas instituciones de garantía, no sólo en materia de seguridad sino también en materia de protección del ambiente y de los derechos vitales para la supervivencia, el gran desafío que proviene de la actual globalización sin reglas. Naturalmente que no hay un nexo directo entre estas grandes emergencias y el terrorismo internacional. Pero es precisamente este nexo, o sea el corto circuito entre terrorismo y consenso de los desheredados del planeta, el que puede fácilmente establecerse. Debemos por tanto preguntarnos si es realista la aspiración a la paz y a la seguridad en un mundo en el que ochocientos millones de personas, o sea una sexta parte de la humanidad, posee el $83 \%$ de la renta mundial, y en el cual la desigualdad entre países pobres y países ricos nunca había alcanzado formas tan vistosas y visibles como en el actual "tiempo de los derechos": pasando de una diferencia de 1 a 3 en 1820 y de 1 a 11 en 1913, a un margen que es de 1 a 100.

Debemos preguntarnos, en otras palabras, si la verdadera utopía ya no es el proyecto de paz diseñado por la Carta de la ONU, sino la idea de que tales desigualdades no están destinadas a convertirse en explosivas y a poner en peligro la paz, la seguridad y nuestras propias democracias. Hoy en día más de mil millones de personas se encuentran privadas de alimentación adecuada y de acceso a agua potable. Diecisiete millones de personas mueren cada año, víctimas de enfermedades infecciosas e incluso antes del mercado, por no haber podido pagar los costos de medicamentos patentados o, peor aún, porque los fármacos banales que los habrían curado no se producen más dado que se destinaban a enfermedades infecciosas en buena medida erradicadas y desaparecidas en los países occidentales. Se ha calculado que una tasa anual equivalente al $1 \%$ de los patrimonios de las doscientas personas más ricas del mundo bastaría para asegurar la educación primaria a todos los niños de la tierra. Esto equivaldría, entre otras cuestiones, a una inversión contra el terrorismo mucho más eficaz que cualquier acción militar: pensemos solamente en el mucho menor alcance que tendría hoy en día el fundamentalismo reli- 
gioso si los Estados Unidos y Pakistán, en vez de financiar en los años de la ocupación soviética de Afganistán las 22,000 escuelas de fanatismo religioso que en estos últimos años han formado a cientos de miles de integristas, hubieran financiado, con el mismo número de escuelas, cualquier programa de educación primaria.

Poner fin a esta gigantesca omisión de socorro no es solamente un deber impuesto por la Declaración Universal de 1948 y por los pactos internacionales de derechos civiles, políticos, sociales y culturales de 1966, sino también - evidentemente - una condición indispensable para garantizar la paz y la seguridad. Es el propio preámbulo de la Declaración Universal de los Derechos Humanos el que establece, realistamente, este nexo entre paz y garantía de los derechos, entre violaciones de derechos humanos y violencia, y por tanto nos advierte que no podemos hablar de paz y de seguridad futuras, ni siquiera para nuestras ricas democracias, si no se remueven o al menos se reducen la opresión, la desigualdad, el hambre y la pobreza de millones de personas, que representan un terrible desmentido de las promesas contenidas en muchas cartas constitucionales e internacionales. 